\title{
Penerapan Pembelajaran Kooperatif Reciprocal Teaching Berbasis Lesson Study untuk Meningkatkan Kemampuan Metakognitif Mahasiswa IKIP Budi Utomo Malang
}

\author{
Dwi Candra Setiawan \\ Program Studi Pendidikan Biologi IKIP Budi Utomo Malang \\ Jalan Citandui 46 Malang \\ e-mail: dwicandra14@gmail.com \\ Erfitra Rezqi Prasmala \\ Program Studi Pendidikan Biologi IKIP Budi Utomo Malang \\ Jalan Citandui 46 Malang \\ e-mail:dphitlah@yahoo.co.id \\ Dyah Ayu Widya Ningrum \\ Program Studi Pendidikan Biologi IKIP Budi Utomo Malang \\ Jalan Citandui 46 Malang
}

\begin{abstract}
The quality of education in Indonesia still needs to be improved both in human resources and components in the learning process. Improving the quality of education is very important because the quality of a nation is determined by the education factor. Education in Indonesia is still emphasis on cognitive learning outcomes, so the ability of other students as metacognitive less empowered. Those problems need to be addressed, either by applying learning strategies Reciprocal Teaching ( RT ) based Lesson Study . Application of Lesson Study based learning is expected to empower metacognitive skills of learners. The purpose of this study is to explain the improvement of the learning process with regard metacognitive skills of students after learning Reciprocal teaching strategies implemented based Lesson Study. This study used two cycles with each cycle has four stages. These stages form a spiral cycle which includes 1 ) planning, 2 ) granting the action, 3 ) observation, and 4 ) reflection. Lesson Study is an improvement of learning undertaken collaboratively by measures planning ( Plan), implementation of the plan learning in the classroom ( Do), and reflection activities that discussions about things that happen in the learning process in the classroom (See). Lesson Study activities aimed at improving the quality of learning that has three stages, namely Plan, Do and See. Samples used in this research is student of Class C in 2014 as many as 45 people. The results showed learning strategies Reciprocal Teaching ( $R T$ ) based Lesson Study can improve student metacognitive ability IKIP Budi Utomo Malang.
\end{abstract}

Keywords: Learning, Cooperative reciprocal Teaching, Lesson Study

Kualitas pendidikan di Indonesia memang masih perlu ditingkan baik dari SDM maupun komponen di dalam proses pembelajaran. Peningkatan kualitas pendidikan ini sangat penting karena kualitas suatu bangsa ditentukan oleh faktor pendidikan. Oleh karena itu, pembaharuan di bidang pendidikan harus selalu dilakukan untuk meningkatkan kualitas pendidikan nasional. Dalam rangka meningkatkan mutu pendidikan dan memperbaiki permasalahan pendidikan di atas, pada tahun 2005 pemerintah dan DPR RI telah mensahkan Undang-Undang RI Nomor 14 Tahun 2005 tentang Pendidik dan Dosen. Undang-undang tersebutmenuntut penyesuaian penyelenggaraan pendidikan dan pembinaan pendidik agar pendidik menjadi profesional.

Berdasarkan hasil pengamatan selama mengajar di IKIP Budi Utomo, diperoleh hasil bahwa kemampuan metakognitif peserta didik sangat kurang diberdayakan. Padahal metakognitif merupakan salah satu kemampuan yang sangat dibutuhkan dan perlu diberdayakan. Corebima (2005) menyatakan bahwa kemampuan 
metakognitif dalam proses pembelajaran sangat penting sekali. Hal ini dikarenakan pada kemampuan metakognitif peserta didik diberdayakan untuk mengambil keputusan yang tepat, cermat, sistematis, dan logis.

Untuk memberdayakan kemampuan metakognitif peserta didik IKIP Budi Utomo dapat dilakukan dengan penelitian tindakan kelas (PTK) berbasis lesson study (LS). Terkait PTK berbasis lesson study di IKIP Budi Utomo berdasarkan hasil observasi dan wawancara kepada mahasiswa dan beberapa dosen Biologi dan Matematika diperoleh bahwa pelaksanaan pembelajaran ini sama sekali belum dilakukan. Berdasarkan hal ini maka penerapan PTK berbasis LS sangat perlu dilaksanakan karena dapat dimanfaatkan sebagai ilmu baru bagi mahasiswa IKIP Budi Utomo serta melatih para mahasiswa untuk belajar menerapkan pembelajaran PTK berbasis LS.

Lesson study yaitu suatu model pembinaan profesi pendidik melalui pengkajian pembelajaran secara kolaboratif dan berkelanjutan berlandaskan prinsip-prinsip kolegalitas dan mutual learning untuk membangun komunitas belajar. Kegiatan Lesson Study awalnya berkembang di Indonesia melalui IMSTEP (Indonesia Methematics and Science Teacher Education Project) yang bekerjasama dengan JICA (Japan InternationalCoopeation Agency). Tujuanumum dari IMSTEP adalah untuk meningkatkan mutu pendidikan matematika dan IPA di Indonesia. Kegiatan Lesson Study dapat menerapkan berbagai metode pembelajaran yang dianggap sesuai dengan permasalahan yang muncul di dalam kelas tersebut. Lesson Study dilaksanakan dalam 3 tahap yaitu plan (perencanaan), do (pelaksanaan) dan see (refleksi).

Pada penelitian ini peneliti menggabungkan Penelitian Tindakan Kelas (PTK) dengan Lesson Study. PTK berbasis LSini menggunakan strategi pembelajaran RT (Reciprocal Teaching). Strategi ini mengandung kegiatan meringkas, menyusun pertanyaan, memprediksi dan mengklarifikasi. Kegiatan meringkas dapat melatih peserta didik mengeloloa informasi. Pada kegiatan ini diperlukan aktivitas membaca, dan merangkum ide. Kegiatan ini dapat mengembangkan ketrampilan metakognisi seperti merancang, memantau dan mengevaluasi (Ibrahim, 2007). Kegiatan selanjutnya adalah menyusun pertanyaan. Pada kegiatan ini akan merangsang peserta didik untuk berlatih berpikir kritis, karean pada kegiatan ini merupakan usaha untuk mengembangkan rasa ingin tahu peserta didik dalam memperoleh informasi (palincsar, 2002).
Kegiatan selanjutnya adalah memprediksi, dimana dalam kegiatan ini peserta didik dilatih untuk mengambil keputusan terhadap suatu permasalahan yang dihadapi peserta didik (Suratno, 2009). Kegiatan terakhir adalah mengklarifikasi. Mengklarifikasi merupakan kegiatan dimana peserta didik melakukan identifikasi informasi. Identifikasi ini dilakukan jika peserta didik dalam menyelesaikan masalah tidak dapat memecahkannya, maka peserta didik dalam kegiatan ini selanjutnya akan berusaha mencari sumber lain untuk mendukung dalam memecahkan maslahnya. Kegiatan PTK dilaksanakan sebanyak 2 siklus, masing-masing siklus diisi kegiatan Lesson Study yang dimulai dari tahap plan, do, dan see. Setelah tahap see selesai pada siklus pertama kemudian dilanjutkan Lesson Study pada siklus kedua yang bertujuan untuk memperbaiki kegiatan Lesson Study pada siklus pertama.

Berdasarkan permasalahan dan pernyataan diatas, maka peneliti ingin mengajukan pelatihan yang berjudul "Penerapan Pembelajaran Kooperatif RT (Reciprocal Teaching) Berbasis Lesson Study (LS) untuk Meningkatkan kemampuan metakognitif Mahasiswa IKIP Budi Utomo Malang."

\section{METODE}

Penelitian ini dilaksanakan dengan menggunakan pendekatan deskriptif kualitatif. Pendekatan deskriptif kualitatif digunakan untuk mengetahui pelaksanaan proses Penelitian Tindakan Kelas (PTK) berbasis Lesson Study. Secara kolaboratif bersama pendidik mitranya dibuat silabus dan RPP sebagai rencana pelaksanaan PTK, sekaligus disiapkan pula perangkat pembelajaran dan Instrumen penelitian PTKnya. RPP didiskusikan bersama mitra dalam kegiatan "Plan" LS untuk lebih disempurnakan lagi. Berikutnya RPP dilaksanakan di kelas dalam kegiatan "Do"-"See"-LS dan sekaligus "Pelaksanaan Tindakan" dan "Observasi" PTK. Segera setelah pelaksanaan tindakan dilakukan tahap "Refleksi" PTK dan LS sebagai dasar untuk perbaikan dalam pertemuan pelaksanaan tindakan PTK berikutnya dan bahan untuk "Plan"LS berikutnya (Susilo, 2012).

Sampel dalam penelitian ini ialah Mahasiswa Biologi IKIP Budi Utomo Jurusan Pendidikan Biologi Angkatan 2014 Kelas C berjumlah 42 Orang. Perangkat pembelajaran yang digunakan dalam penelitian ini adalah silabus, rencana pelaksanaan pembelajaran (RPP), lembar Kerja 
Mahasiswa (LKM RT). Instrumen yang digunakan untuk mengukur variabel terikat adalah menggunakan rubrik kemampuan Metakognitif.

Data penelitian ini berupa data kuantitatif yaitu skor dari rubrik metakognitif dengan hasil pengerjaan LKM. Data hasil ini dikumpulkan melalui hasil yang diperoleh dari siklus I dan II untuk mengetahui peningkatan kemampuan metakognitif mahasiswa.

\section{HASIL}

Penilaian keterampilan metakognitif mahasiswa dilihat berdasarkan hasil perhitungan skor padarubrik penilaianketerampilanmetakognitif. Penilaian keterampilan metakognitifini dinilai secara berkelompok berdasarkan hasil produk yang dirancang dan dibuat yaitu berupa sintaks kegiatan pembelajaran sederhana beserta mediamedia pembelajaran yang dipilih, ditetapkan, dirancang dan digunakan dalam sintaks kegiatan pembelajaran tersebut.

Terdapat delapan kelompok mahasiswa, dan penilaian keterampilan metakognitifini dinilai oleh Dosen Model pada saat kelompok memodelingkan hasil rancanga produknya di depan kelas. Berdasarkan hasil penilaian, dapat dilihat persentasi hasil penilaian siklus I pada kelompok 1, 2, 3, 4, 5, 6, 7 dan 8 secara berturutturut adalah $67 \%, 92 \%, 48 \%, 92 \%, 67 \%, 67 \%$, $67 \%$ dan 92\% Sehingga peneliti (Dosen Model) menghitung akumulasi dari jumlah skor-skor yang diperoleh tersebut dan diperoleh bahwa persentasi keterampilan metakognitifmahasiswa pada siklus I ini adalah sebesar $69,44 \%$. Sedangkan Untuk Siklus II diperoleh persentasi hasil penilaian pada kelompok secara berturut-turut adalah $83 \%, 100 \%, 83 \%, 92 \%, 83 \%, 80 \%$., 83\% dan $92 \%$.

\section{Tabel 2.1 Perbandingan Hasil Kemampuan Metakognitif}

\begin{tabular}{cc}
\hline Tindakan & $\begin{array}{c}\text { Presentase Kemampuan } \\
\text { Metakognitif }\end{array}$ \\
\hline Siklus I & $69 \%$ \\
Siklus II & $88,38 \%$ \\
\hline
\end{tabular}

Berdasarkan Tabel 4.1 dapat dilihat bahwa peningkatan dari siklus I ke siklus II sebesar 19, 38\%. Hal ini menunjukkan adanya keberhasilan pembelajaran RT berbasis LS dalam meningkatkan kemampuan metakognitif mahasiswa.

\section{PEMBAHASAN}

Berdasarkan hasil penelitian dan analisis data menunjukkan Reciprocal Teaching, mampu memberdayakan kemampuan metakognitif dikarenakan dalam sintaksnya sangat menunjang untuk mahasiswa memberdayakam metakognitifnya, seperti pada tahap meringkas dan membuat pertanyaan. Pada tahapan ini mahasiswa dituntut untuk mau membaca dan kemudian berusaha untuk membuat ringkasan serta membuat pertanyaan. Dengan membaca serta membuat ringkasan maka akan melatih pola berpikir mahasiswa untuk memahami apa yang dibaca. Hal ini diperkuat oleh Slavin (2006), yang menyatakan membuat pertanyaan dan menjawabnya sendiri, membuat ringkasan, atau mengucapkan dengan kata-kata sendiri apa yang telah mereka dengar merupakan strategi metakognitif yang dapat mendorong berkembangnya kesadaran metakognitif.

Tahap membuat ringkasan, pertanyaan, memprediksi dan mengklarifikasi dalam RT menyumbangkan peran yang penting dalam meningkatkan kemampuan metakognitif. Blank (tanpa tahun) menyebutkan bahwa strategi pembelajaran yang melibatkan kegiatan memprediksi dan mengevaluasi prediksi, membuat pertanyaan, dan menjawab pertanyaan (questioning and answering relationship), dan kegiatan meringkas merupakan strategi metakognitif. Membuat ringkasan, pertanyaan, prediksi, dan klarifikasi merupakan bentuk dari pendekatan student centered sebagai komponen utama dari tahap reciprocal teaching dan mendorong munculnya self-regulation pada sebagian besar siswa (Doolittle, 2006).

Peningkatan kemmapuan metakognitif mahasiswa pada penelitian ini juga dikarenakan dilakukan dengan pembelajaran berbasis Lesson Study. Penerapan model pembelajaran RT berbasis Lesson Study akan semakin mampu memberdayakan kemampuan metakognitif siswa. Hal ini dikarenakan pada Lesson Study, sebelum proses pembelajaran berlangsung akan dilakukan perencanaan pemeblajaran yang lebih baik dengan melibatkan banyak orang selain dari Dosen model. Dengan adanya kolaborasi antara Dosen Model dengan beberapa rekan dalam hal ini disebut Observer akan menghasilkan suatu perencanaan pembelajaran yang jauh lebih baik dan rinci. Kehadiran observer dalam kegiatan plan di LS akan memberikan saran, tambahan serta masukan untuk Dosen model dalam membuatperencanaanpembelajaran, sehinggadengan hal demikian akan memperbaiki kekurangan 
dari perangkat pembelajaran, alat, bahan, media pembelajaran, dan instrumen penilaian, serta teknik pembelajaran oleh dosen model pada pelaksaan do dari lesson study. Pernyataan di atas juga didukung teori yang dikemukakan oleh Garfield (2006) dalam Ibrohim (2010) menyatakan bahwa lesson study adalah proses sistematis yang digunakan guru-guru Jepang untuk menguji keefektifan pengajarnya dalam rangka meningkatkan hasil pembelajaran.

Lewis (dalam Ibrohim, 2009) juga menambahkan bahwa lesson study menciptakan "multiple pathways of learning" yang meningkatkan pengajaran guru, yakni: (1) meningkatkan pengetahuan tentang bahan ajar; (2) meningkatkan pengetahuan tentang pengajaran; (3) meningkatkan kemampuan untuk mengamati siswa; (4) lebih menguatkan jaringan kolegial; (5) lebih menguatkan jalinan antara praktik pengajaransehari-haridengantujuan pendidikan jangka panjang; (6) menguatkan motivasi dan kepekaan; (7) meningkatkan kualitas rencana pembelajaran.

Dalam Penelitian kali ini juga dikatakan mampu memberdayakan kemampuan metakognitif juga dapat dilihat dari hasil angket yang diberikan oleh Dosen kepada Mahasiswa di akhir pertemuan siklus II. Dimana lebih dari $70 \%$ mahasiswa merasa kemampuan berpikir dan pemahamannya terhadap materi semakin meningkat dengan ditepkannya PTK berbasis Lesson Study. Para mahasiswa juga cukup puas dengan penerapan pembelajaran PTK berbasis Lesson Study.

\section{KESIMPULAN DAN SARAN}

Berdasarkan hasil penelitian menunjukkan dapat di simpulkan bahwa penelitian tindakan kelas (PTK) berbasis Lesson Study dengan Menggunakan model pembelajaran Reciprocal Teaching dapat meningkatkan kemampuan metakognitif mahasiswa. Dengan hasil penelitian ini maka model Reciprocal Teaching dapat digunakansebagaialternatif model pembelajaran yang dapat digunakan pada pembelajaran sehari-hari, terutama dalam meningkatkan kemampuan tingkat tinggi seperti metakognitif, berpikir kritis dan berpikir kreatif. Penerapan Lesson Study sebaiknya terus dilatih kepada mahasiswa agar semakin terlatih dan terbiasa untuk melaksanakannya.

\section{DAFTAR RUJUKAN}

Arikunto, S. 2002. Prosedur Penelitian (Suatu Pendekatan Praktek). Jakarta: PT. Rineka Cipta.

Blank, M. A. Tanpa tahun. Metacognitive Strategies, Brainstorming List of Instructional Strategies that Promote Metacognitive Thinking. (online) (http://web.utk.edu/- mblank/pdf/ d5strats/metacognitivestrategies.pdf), diakses tanggal 10 Juli 2015.

Corebima, A. D. 2005. Pelatihan PBMP (Pemberdayaan Berpikir Melalui Pertanyaan) Pada Pembelajaran Bagi Para Dosen dan Mahasiswa Sains Biologi dalam rangka RUKK VA. 25 Juni

Corebima, A. D. 2008a. Dosen Anak Bangsa. Makalah disajikan pada pelatihan pembelajaran Kooperatif TPS dan Jigsaw dengan strategi metakognitif pada dosen-dosen Biologi di SMAN Kota Pekanbaru. 5 Mei 2008.

Doolittle, P. E., Hick, D. dan Triplett, C.F. 2006. Reciprocal Teaching for Reading Comprehension in Higher Education: A Strategy for Fostering The Deeper Understanding of Texts. International Journal of Teaching and Learning in Higher Education. 17 (2): 106-118. ISSN 1812-9129. Http://www. Isetl.org/ ijtlhe/pdf/IJTLHE1.

Ibrohim. 2009. Pengaruh Model Implementasi Lesson Study dalam Kegiatan MGMP terhadap Peningkatan Kompetensi Guru dan Hasil Belajar Biologi Siswa. Disertasi tidak diterbitkan. Malang: PPs UM.

IbrohimdanSyamsuri.2010.LessonStudySebagai Pola Alternatif untuk Meningkatkan Efektivitas Praktik Lapangan (PPL) Mahasiswa Calon Guru. Makalah disajikan dalam Workshop lesson study untuk Mahasiswa, guru, dan dosen, FMIPA Universitas Negeri Malang, Malang, 28 Februari.

Lewis, C. 2002. Lesson Study: A crafting Learning Together, (Online), (http:// www.nwrel.org/msec/nwteacher/ spring2003/elements.html, diakses 10 Juli 2015). 
Nurhadi. 2004. Pembelajaran Kontekstual dan Penerapannya Dalam KBK. Malang: UM Press.

Palinscar, A.S, dan Brown, A. L. 1984. Reciprocal Teaching of Comprehension Fostering and Comprehension Monitoring Activities. Hillsdale, NJ: Lawrence Erlbaum Associates, Inc.

Setiawan, Dwi Candra., 2015. Pengaruh Strategi pembelajaran Resiprokal Teaching (RT) Dipadu Pemberdayaan Berpikir Melalui Pertanyaan (PBMP) Terhadap Kemampuan Metakognitif, Berpikir Kritis dan Pemahaman Konsep Biologi Mahasiswa SMA Islam Al Ma'arif Singosari Malang. Tesis tidak diterbitkan. Malang: PPs UM.

SISTTEMS NEWSLETTER. 25 Desember, 2006. Training Lesson Study di Jepang, No.3.

Slavin, R. E. 2006. Educational Psychology Teory and Practise. New York: Pearson and Education. Inc.

Susilo, H. 2005. Lesson study: Apa dan Mengapa. Malang: JICA-IMPSTEP.
Susilo, H. 2006. Apa dan Mengapa Lesson Study Perlu Dilakukan untuk Meningkatkan Profesionalisme Pendidik dan Dosen MIPA. Makalah. Disajikan dalam Seminar Peningkatan Profesionalisme Pendidik dan Dosen MIPA melalui LessonStudy, diSingaraja, 25November 2006.

Susilo, H. 2009. Lesson Study Berbasis Sekolah Pendidik Konservatif Menuju Pendidik Inovatif. Malang: Bayumedia Publishing

Susilo, H. 2010. Lesson Study Berbasis MGMP Sebagai Sarana Pengembangan Keprofesionalan Guru. Malang: Surya Pena Gemilang.

Susilo, H. 2010. Peran Lesson Study Dalam Meningkatkan Profesionalitas Pendidik Dan Kualitas Pembelajaran. Makalah disajikan dalam Prosiding Seminar Nasional Lesson Study 3, FMIPA UM, Malang, 9 Oktober.

Winkel, W.S. 1996. Psikologi Pengajaran. Jakarta: Gramedia. 
118 | Dwi Candra Setiawan, dkk., Penerapan Pembelajaran Kooperatif ... 